\title{
PUBLICIDAD EN INTERNET: NUEVAS VINCULACIONES EN LAS REDES SOCIALES
}

Estrella Martínez-Rodrigo1: Universidad de Granada. España emrodrigo@ugr.es

Lourdes Sánchez-Martín: Universidad de Granada. España lousanm@correo.ugr.es

\section{RESUMEN}

La evolución de la publicidad se ha producido paralelamente al de las TIC. De este modo, la publicidad se insertó rápidamente en Internet y, en la actualidad, lo ha hecho en las nuevas plataformas on line en auge: las redes sociales. El cambio que ha experimentado la publicidad se manifiesta tanto narrativa como formalmente. Por una parte, su discurso enfatiza valores añadidos frente a las características del producto de la publicidad convencional. Por otra, las redes sociales han permitido la interactividad y participación dinámica de los potenciales consumidores. A continuación se analizarán estas diferencias entre la publicidad tradicional y la actual para, finalmente, centrarnos en los perfiles de marca, los cuales han establecido nuevas vinculaciones entre los potenciales clientes y las marcas.

PALABRAS CLAVE: Publicidad - Redes sociales - Marca - Valor - Emoción

\section{${ }^{1}$ Autor correspondiente}

Estrella Martínez-Rodrigo: Doctora Profesora de Comunicación Audiovisual. Facultad de Documentación y Comunicación. Universidad de Granada. Granada, España. 


\title{
INTERNET ADVERTISING: NEW LINKS IN SOCIAL NETWORKS
}

\begin{abstract}
The evolution of advertising has occurred in parallel with the Information Technologies and Communication. Thus, advertising on the Internet and quickly inserted, at present, it has in the booming new platforms: social networks. The change experienced advertising is seen both narrative and formally. On the one hand, his speech emphasizes added value to the product characteristics of conventional advertising. In addition, social networks have allowed interactivity and active participation of potential users. Following is an analysis of these differences between the conventional and current advertising to finally focus on brand profiles, which have established new connections between potential customers and brands.
\end{abstract}

KEY WORDS: Advertising - Social networking - Brand - Value - Emotion

\section{INTRODUCCIÓN}

\subsection{El nuevo discurso publicitario: del producto al valor}

Desde su origen, el objetivo de la publicidad ha sido persuadir a potenciales clientes con la finalidad de que consumiesen el producto anunciado. En sus inicios, el discurso publicitario mostraba las características básicas del objeto, sus atributos propios y sus bondades. Sin embargo, esta narrativa ha ido evolucionando hasta la actualidad, en donde predomina un discurso centrado en la venta de emociones y experiencias. Se ha avanzado de un discurso denotativo a un discurso simbólico, en donde este mismo simbolismo establece el valor diferencial del producto con respecto a otros similares. No se vende el artículo de forma directa, sino que se apela a significados concretos, universalmente conocidos $\mathrm{y}$, por tanto, fácilmente identificables, que son los deseados por el receptor. Estos elementos simbólicos en venta son emociones asociadas al consumo del producto.

Queda en el pasado la publicidad que se destacaba por resaltar los beneficios de los productos. Hoy en día, esos beneficios no siempre pueden ser racionales, porque todos ofrecen ventajas similares; esto explica la proliferación de la publicidad emocional, donde se destacan ante todo valores asociados a deseos, anhelos y aspiraciones internas de los individuos (López, 2007, p. 29). 
Las necesidades conocidas y no satisfechas impulsan a los individuos a actuar de modo que esas necesidades puedan verse cumplidas. Precisamente conocer esas necesidades y adecuar su mensaje a ellas será una de las misiones previas del persuasor si es que quiere conducir a su audiencia al punto prefijado (León, 1989, p. 258)

La publicidad establece así un discurso unitario pero no único, centrado en el estilo o valor asociado y que mejora la relación mental del receptor entre el elemento simbólico, la marca y el producto, facilitando la fidelización, que requiere ir más allá del artículo y sus características, creando una fuerte connotación emocional (Alcaide, 2010). No se difunden tan solo las ventajas de unos objetos sobre otros.

Se trata de un sistema que intenta persuadir al receptor de la conveniencia de un artículo apelando a emociones y beneficios, muchas veces psicológicos, que podrá experimentar al consumirlo. Como señala Lomas (1999), con la publicidad se crean ilusiones, se muestran estilos de vida o experiencias deseables y, al mismo tiempo, se crean hábitos de consumo. La publicidad ya no habla solamente del producto, sino también del universo del potencial consumidor, recurre al imaginario colectivo y apela a valores deseados y un tanto inalcanzables. Se trata de "una práctica significante cuyo poder reside en su capacidad para producir y reproducir el sentido de una cultura" (Arroyo \& Mamic, 2009, p. 14).

Es interesante lo que señala Sáez sobre los spots audiovisuales, aunque sus afirmaciones son también aplicables a las nuevas estrategias publicitarias en la red:

Los valores en juego se ordenan en sistemas de razonamiento, en general, en silogismo. Las premisas de estos silogismos aluden a las implicancias y actos de habla subyacentes en el texto visual y lingüístico presentes. [...] Así, nos propone una manera de entender los valores sociales en juego, que será la forma de razonar que a ellos les conviene para convencernos de que, con los productos, vamos a cumplir con la forma ideológica que inculcan (Sáez, 2003)

Estas emociones y valores presenten en la publicidad tradicional se patentizan también en las actuales campañas en Internet.

\section{METODOLOGÍA}

La presente investigación toma como base metodológica el método comparativo para analizar las diferencias entre la publicidad tradicional y la actual para, finalmente, caracterizar los perfiles de marca, los cuales han establecido nuevas 


\section{ANÁLISIS Y DISCUSIÓN}

\subsection{La publicidad en Internet}

La introducción de la World Wide Web se acabó imponiendo en la década de los 90 del pasado siglo. El ámbito de la publicidad encontró rápidamente en la red una potencial herramienta para ampliar sus ventas y expandir su mercado. Internet comenzaba a ser una ventana abierta al mundo, a través de la cual las marcas podían llegar hasta lugares y públicos insospechados. De este modo, algunos anunciantes comenzaron a aparecer en la red, en páginas web sencillas, cuyo contenido era principalmente textual. Los diferentes modos de publicidad rápidamente proliferaron: pop ups, banners, skycrapers, intersitiales, etc. y las posibilidades se multiplicaron. Es cierto que:

Como medio publicitario, el valor más destacable de Internet es que ha permitido el acceso a todo tipo de anunciantes sin importar el tamaño o naturaleza del mismo. [...] Es lo que se llama la democratización de la publicidad (Muela Molina, 2008, p. 185)

La publicidad en la red introdujo fundamentalmente tres elementos significativos. En primer lugar, los usuarios ya no tenían que acceder a la web oficial de la marca o producto. Los banners se introducían en cualquier web, pudiendo atraer la atención de consumidores potenciales que, de otro modo, no hubieran accedido a la información. Por otra parte, facilitó la segmentación de públicos y la personalización de la publicidad, ya que una misma marca podía realizar anuncios diferentes según los receptores a los que se dirigía; por ejemplo, una misma marca podía insertar un reclamo publicitario en una web destinada a jóvenes y otro diferente en una página destinada a adultos.

Finalmente, se introdujo una mínima interactividad, en donde los usuarios podían incluso interactuar ociosamente con los banners, mediante una participación activa. Segmentación, personalización, interactividad y participación activa, son componentes Fundamentales que establecen una radical diferencia entre la publicidad convencional y la publicidad en la red. Estos elementos se han intensificado aún más en las actuales comunidades virtuales. 


\subsection{Perfiles de marca: publicidad en las redes sociales}

En la última década han aparecido nuevas herramientas en la red que han adquirido un gran auge. La web 1.0 o web estática ha sido relegada por la web social (2.0), dado su potencial para la generación de contenidos. Ya se habla de la Web Semántica o 3.0, pero, mientras tanto, han aparecido nuevas plataformas que han adquirido un gran número de adeptos. Las redes sociales como Facebook o Tuenti han experimentado un incremento notable de usuarios habituales. El ámbito de la publicidad ha sabido insertarse rápida y eficazmente en estas redes, mediante la realización de perfiles oficiales de marca, los cuales encuentran en estas plataformas un modo eficiente de aproximarse a clientes potenciales a bajo coste.
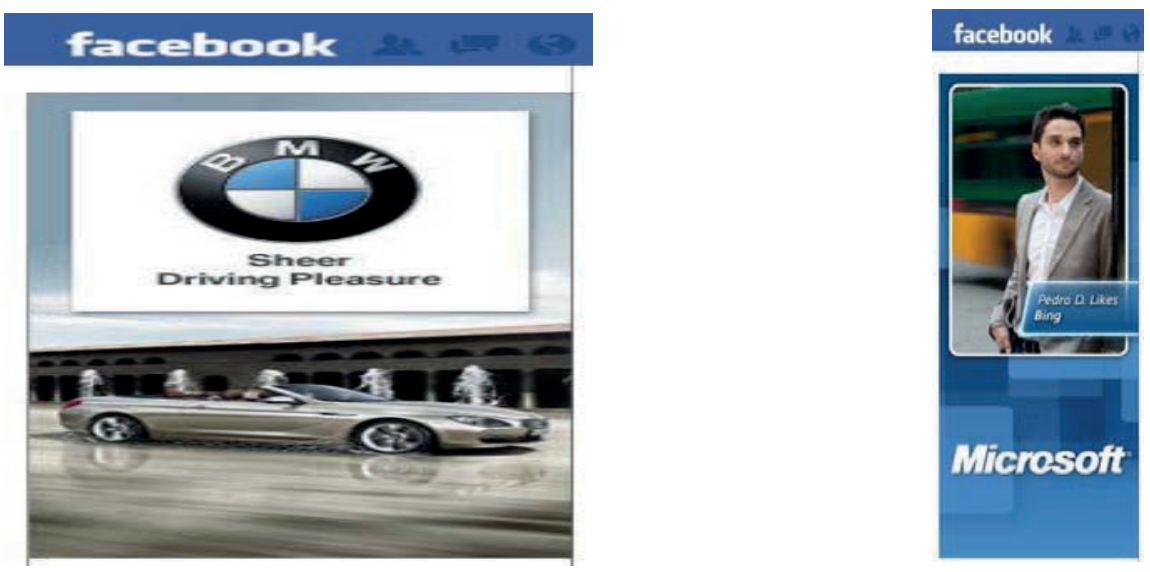

Figura 1. Perfiles de marca en Facebook: BMW y Microsoft. Fuente: www.facebook.com

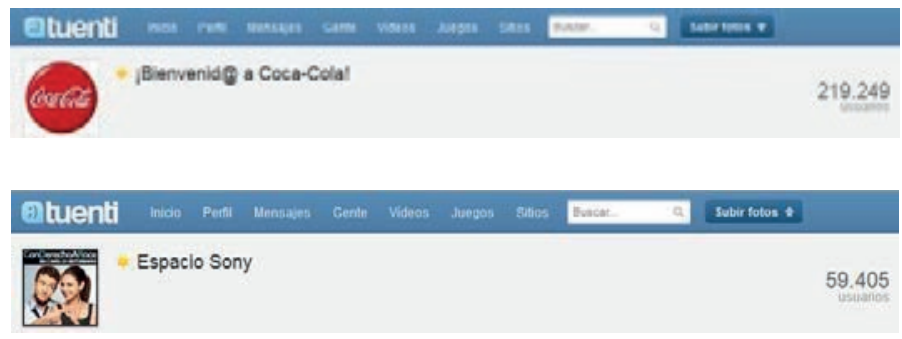

Figura 2. Perfiles de marca en Tuenti: Coca-Cola y Sony.

Fuente: $\underline{w w w . t u e n t i . c o m}$ 
La publicidad no ha evolucionado solo narrativamente sino también formalmente. Ya no se trata de la publicidad convencional de la web estática (banners, pop ups...) sino que los perfiles se caracterizan por la interactividad, incluyendo diferentes soportes: imágenes, comunicación directa y bidireccional, vídeos, spots, juegos,... La interactividad (además del discurso de la marca) es un elemento esencial en la generación de una actitud o emoción determinada con respecto la marca o producto en estas plataformas. La inmediatez, la personalización y la participación son rasgos determinantes en este proceso (Martínez Rodrigo, Segura García y Sánchez Martín, 2011, p. 186).

En las redes sociales "el advertainment se impone. Eso sí, se observa que intentan aportar un valor añadido para ser perdonados por su intrusismo" (De Salas, 2010, p. 32). Y ese valor añadido es justamente el valor o emoción en venta, propio de su discurso simbólico, y que se manifiesta en los diferentes soportes. Las marcas intentan ofrecer además contenidos ociosos. Como señala Marina Ramos (2006), se trata de una simbiosis entre publicidad y entretenimiento cuyo objetivo es captar la atención del público de forma atractiva hacia los valores de la marca. Así, en el perfil de Coca-Cola en Tuenti, el anunciante ofrece diferentes contenidos destinados a adolescentes, que se insertan dentro del advertainment y advergaming, creando experiencias lúdicas en el receptor, como se muestra en las siguientes imágenes:

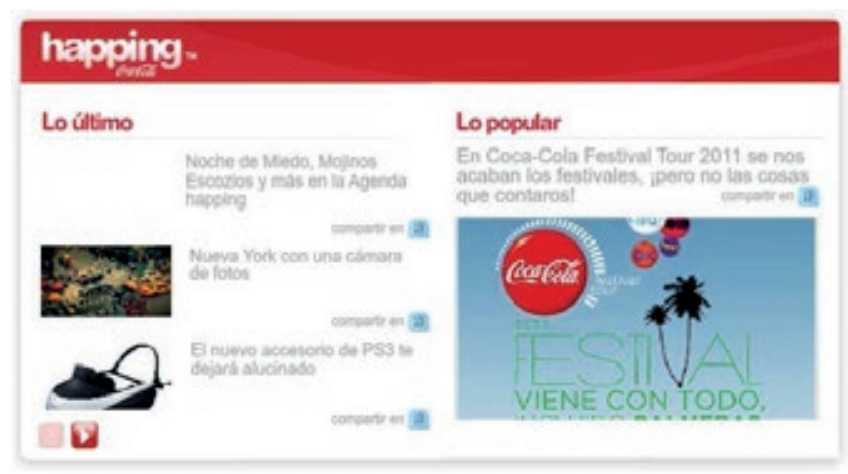

Figura 3. Advertainment: Coca-Cola en la red social Tuenti Fuente: www.tuenti.com 


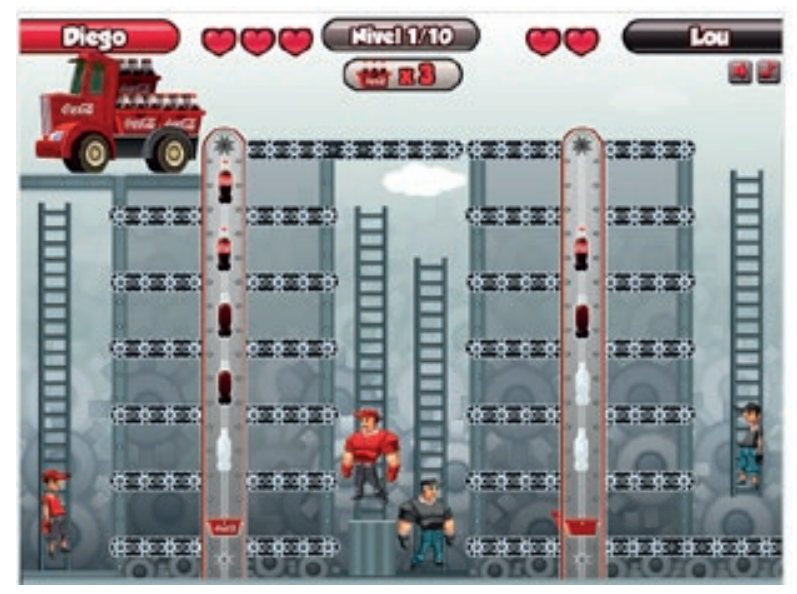

Figura 4. Advergaming: Coca-Cola en la red social Tuenti Fuente: www.tuenti.com

Estos contenidos crean una participación activa de los usuarios y, por tanto, una consideración positiva de la marca al asociarla con la diversión y las emociones positivas.

Existe además otro elemento determinante en estos perfiles publicitarios: la comunicación. Ésta es esencial para lograr una vinculación emocional por parte de los receptores, lo cual facilita que estos deseen el valor añadido (o emoción) que ofrece el producto. Parece claro que:

No se puede crear una relación emocional con los clientes si no existe la correcta y adecuada comunicación. Esta realidad contrasta con una característica muy bien estudiada en la sociedad moderna: la escasa influencia que tienden a tener los medios de comunicación masivos en los comportamientos de los consumidores y usuarios, además de que dichos medios no son eficaces cuando se trata de crear un vínculo emocional duradero. Esto último sólo se logra mediante la comunicación directa y personalizada, uno-a-uno, entre la organización y sus clientes" (Alcaide, 2010, p. 22)

Los anunciantes utilizan estos perfiles para entablar una comunicación personalizada entre la marca y el cliente. La tecnología actual y, concretamente las redes sociales, permiten conocer más que nunca a las audiencias, facilitando así el ideal de la personalización de los contenidos y de la publicidad one to one. Un ejemplo de esta comunicación personalizada se produce en el perfil de Coca-Cola en Tuenti: 


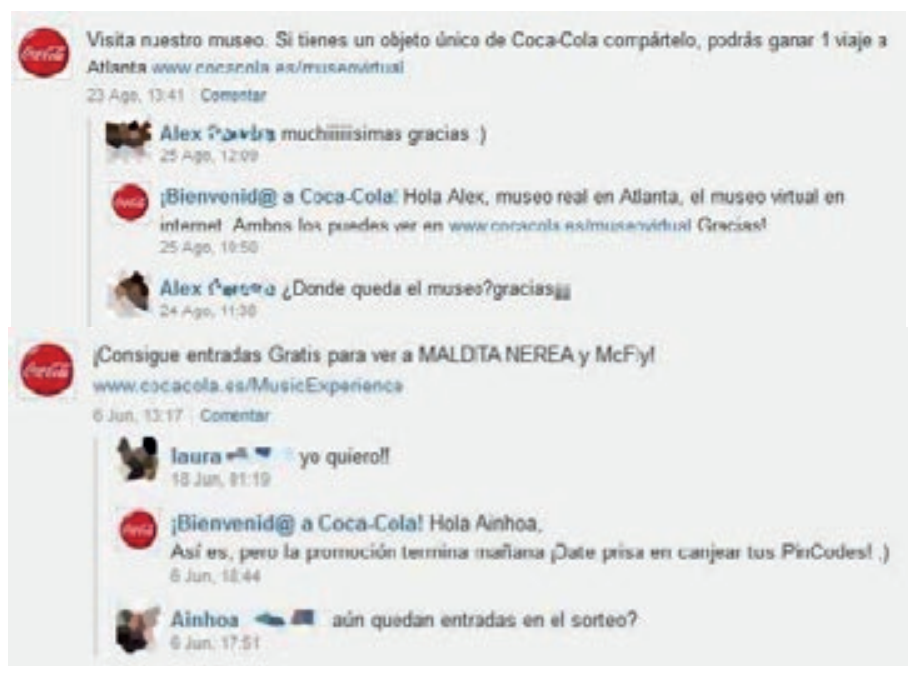

Figura 5. Comunicación directa y personalizada entre marca y clientes: Coca-Cola en Tuenti.

Fuente: $\underline{w w w} \cdot$ tuenti.com

Los perfiles públicos y oficiales en las redes sociales intensifican su discurso simbólico. De este modo, no solo los usuarios asocian a sus experiencias lúdicas la marca y el producto, sino también el valor añadido.

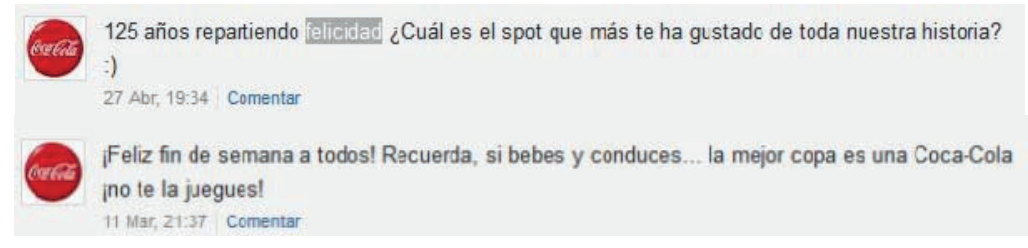

Figura 6. El valor de la felicidad: Coca-Cola en Tuenti.

Fuente: www.tuenti.com

\subsection{Nuevas vinculaciones en las redes sociales}

Las redes sociales han configurado una nueva relación marca-producto-consumidor. Por una parte, los productos que eran el elemento más relevante en la publicidad convencional han sido sustituidos por la marca en los entornos digitales. Los tradicionales spots en televisión se centraban primero en el producto y después en la marca. Podemos recordar así numerosos anuncios de vehículos en donde lo relevante era esta junto con el modelo. Sin embargo, en las redes sociales, la marca es elemento principal de difusión y el que aúna a los usuarios. 
Por otra parte, los contenidos publicitarios han pasado del intrusismo al consentimiento por parte de los usuarios, los cuales se afilian voluntariamente a los perfiles de marca. Estos les ofrecen entretenimiento, a través de contenidos propios del advertainment y advergaming. Los usuarios interactúan con la marca y el producto, participan activa e inexorablemente, y su experiencia lúdica les produce la percepción positiva del anunciante. Esta sensación es trascendental en el público joven, ya que, como algunos apuntan, facilita la temprana fidelización (Martí, 2010).

Las comunidades virtuales permiten una comunicación directa entre anunciantes y consumidores. Se produce así una aproximación de la marca y también de sus productos a los potenciales clientes a través de la red, como ya hemos visto con CocaCola en la comunidad social Tuenti.

Como se ha señalado, "en la medida en que las marcas sean capaces de humanizarse, también lo son de generar lazos afectivos en el área comercial con sus clientes y consumidores, tanto actuales como potenciales" (Rosales, 2010, p. 87), Los usuarios se sienten escuchados, atendidos, protagonistas y parte integrante del grupo. Esto se acentúa si, además, las marcas aprovechan la segmentación de públicos propia de las redes sociales y ofrecen contenidos más atractivos y sugerentes a cada perfil de público. Por ejemplo, mientras en Tuenti predomina el público adolescente, en Facebook lo hace el joven. Las marcas pueden, de este modo, lanzar diversas campañas y potenciar la eficacia de sus reclamos publicitarios.

A través de estos perfiles, los anunciantes intentan vender sus productos entablando una comunicación directa con los usuarios, facilitándoles diversos entretenimientos, transmitiéndoles la sensación de ser escuchados y parte integrante del grupo; al mismo tiempo, las marcas acentúan de esta forma su discurso simbólico, intensificando la relación entre ella, el producto y el valor o emoción asociados al mismo.

La relación marca-producto-consumidor es en estos entornos digitales más estrecha que nunca. Los anunciantes jamás se relacionaron como ahora de una forma tan directa y personalizada con sus potenciales clientes, que son ahora participantes activos en la publicidad. Pueden dialogar con la marca de un modo inmediato, opinar, conocer sus nuevos productos o campañas, interactuar, disfrutar de contenidos de diversa índole e incluso publicitar ellos mismos los productos a través de sus perfiles personales. 


\section{CONCLUSIONES}

El ámbito de la publicidad ha evolucionado narrativa y formalmente. Por una parte, el discurso, que antes estaba centrado en las bondades del producto, ha quedado relegado al olvido para, en la actualidad, enfatizarse los valores asociados a él. Por otra, el desarrollo que han experimentado las TIC ha favorecido la presencia de la publicidad en Internet $\mathrm{y}$, en los últimos años, en las nuevas plataformas on line en auge: las redes sociales.

En éstas, anunciantes y usuarios se mantienen en contacto a través de los perfiles de marca, lo que ha supuesto un cambio profundo en el ámbito publicitario, creando una nueva vinculación entre las marcas y los consumidores. Por ello, la publicidad se está centrando en proporcionar a sus potenciales clientes experiencias lúdicas, información -que se confunde con publicidad- interactividad, participación activa, y la sensación de sentirse escuchados, asegurando de este modo la fidelización de los usuarios.

\section{REFERENCIAS}

Alcaide Casado, J. C. (2010). Fidelización de clientes. Madrid: ESIC.

Arroyo Almaraz, I. \& Mamic, L. I; (2009). Valores occidentales en el discurso publicitario audiovisual argentino. Revista Icono14, 13: 08-23. Recuperado el 20 de junio de 2011, de http://www.icono14.net/revista/num13/1_icono13_isidoroarroyo_liliaivana.pdf.

De Salas Nestares, $\mathrm{M}^{\mathrm{a}}$ I. (2010). La publicidad en las redes sociales: de lo intrusivo a lo consentido. Hologramática, VII(13): 25-36. Recuperado el 20 de mayo de 2011, de http://www.cienciared.com.ar/ra/usr/3/1006/hologramatica13_v2pp25_36.pdf.

Del pino, C. (2007). El anunciante en la era de la saturación publicitaria: Nuevas herramientas de comunicación. Ámbitos, 16: 299-309. Recuperado el 12 de junio de 2011, de http://grupo.us.es/grehcco/ambitos_16/16pino.pdf.

León, J. L. (1989). Persuasión de masas: psicología y efectos de las comunicaciones sociopolíticas y comerciales. Bilbao: Deusto.

Lomas, C. (1999). La seducción de los objetos y la identidad de los sujetos: el discurso de la publicidad. Revista de Ciències de la Informació, 9. Recuperado el 2 de junio de 2011, de 
López Vázquez, B. (2007). Publicidad emocional. Estrategias creativas. Madrid: ESIC.

Martí Parreño, J. (2010). Marketing y videojuegos. Product placement, in-game advertising y advergaming. Madrid: Esic.

Martínez Rodrigo, E.; Segura García, R. \& Sánchez Martín, L. (2011). El complejo mundo de la interactividad: emociones y redes sociales. Revista Mediterránea de Comunicación, 2: 171-190. Recuperado el 20 de agosto de 2011, de http://www.rmedcom.org/2011/1110/1110Martinez.pdf.

Muela Molina, C. (2008). La publicidad en Internet: situación actual y tendencias en la comunicación con el consumidor. Zer. Revista de Estudios de Comunicación, 13(24): 183201). Recuperado el 22 de marzo de 2011, de http://www.ehu.es/zer/zer24/zer24muela.pdf.

Ramos, M. (2006). Cuando la marca ofrece entretenimiento: aproximación al concepto de Advertainment. Questiones Publicitarias, I (11): 33-49. Recuperado el 25 de junio de 2011, de

http://www.maecei.es/pdf/n11/articulos/cuando_la_marca_ofrece_entretenimient o_aproximacion_al_concepto_de_advertainment.pdf.

Rosales, P. (2010). Estrategia digital. Cómo usar las nuevas tecnologías mejor que la competencia. Barcelona: Deusto.

Sáez, N. (2003). Análisis lingüístico del discurso argumentativo subyacente en algunos spots publicitarios que influyen en nuestra ideología social. Cyber Humanitatis, 27. Recuperado el 19 de mayo de 2011, de http:// www.revistas.uchile.cl/index.php/RCH/article/view/5697/5565. 


\section{Estrella Martínez Rodrigo}

Profesora de la Facultad de Comunicación y Documentación de la Universidad de Granada, es Doctora en Comunicación Audiovisual. Su docencia e investigación se han desarrollado en torno al análisis de la web 2.0 y del discurso audiovisual y publicitario, prestando particular atención a sus efectos y a sus implicaciones educativas y de género. Es autora de varios libros. También ha publicado varias decenas de comunicaciones en actas de congresos. Actualmente es la responsable del Grupo de Investigación CiberA $V$ "Cibercultura, Procesos Comunicativos y Medios Audiovisuales" (SEJ 508) de la Junta de Andalucía. Actualmente forma parte del Proyecto de Innovación Docente "Cine y literatura como herramientas didácticas", de la Universidad de Granada (PID 10-238), del Proyecto de Excelencia, "La competencia audiovisual de la ciudadanía andaluza: estrategias de alfabetización mediática en la sociedad del ocio digital" de la Junta de Andalucía. P10-SEJ-5823, y del Proyecto I+D "La Enseñanza obligatoria ante la competencia en comunicación audiovisual en un entorno digital".

\section{Lourdes Sánchez Martín}

Licenciada en Filosofía y Licenciada en Comunicación Audiovisual por la Universidad de Granada, Máster en Traducción y Mediación Lingüística de las lenguas Española y Alemana y Máster en Dirección de Comunicación. Miembro del grupo de investigación CiberAV "Cibercultura, procesos comunicativos y medios audiovisuales" (SEJ 508). Su investigación se centra en el estudio de las redes sociales y de la publicidad en Internet. Colabora también en el Proyecto de innovación docente "Cine y literatura como herramientas didácticas" (PID 10-238). Forma parte del Grupo Comunicar, de la Sociedad Española de Lenguas Modernas y de la Asociación española de investigación de la Comunicación (AE-IC). Es autora de diferentes capítulos de libros, artículos en revistas de Comunicación y de diversas comunicaciones en Actas de Congresos internacionales. Actualmente, trabaja profesionalmente como Community Manager en diferentes plataformas y como docente en cursos de formación sobre Social Media. 